\title{
ASPECTOS PRODUTIVOS DA INDÚSTRIA DE MADEIRA SERRADA NO MUNICÍPIO DE SÃO GABRIEL (RS)
}

\author{
Caroline Soares Silveira* \\ Ana Julia Teixeira Senna Sarmento Barata** \\ Ricardo Ribeiro Alves***
}

RESUMO: A cadeia produtiva florestal é composta por um conjunto de atividades que se articulam desde a produção de insumos até a comercialização. No município de São Gabriel (RS) este setor é composto por empresas que atendem, principalmente, ao setor da construção civil. Este trabalho analisou a cadeia de produção da madeira serrada no município de São Gabriel (RS). Para a obtenção dos dados foram realizadas onze entrevistas semiestruturadas com empresas do setor florestal. Posteriormente, as entrevistas foram transcritas e analisadas. Os resultados encontrados revelam que não há uma cadeia de produção de madeira serrada estruturada e os elos envolvidos neste processo trabalham separadamente, sem integração. Este fato ocorre devido à falta de insumos e de produção local e a recente emergência do setor florestal no município.

PALAVRAS-CHAVE: Cadeia produtiva; Madeira; Setor florestal.

\section{PRODUCTION ASPECTS OF THE TIMBER INDUSTRY IN THE TOWN OF SÃO GABRIEL, BRAZIL}

ABSTRACT: The forest production chain comprises a set of activities which range from the production of inputs till commercialization. The production sector in the town of São Gabriel RS Brazil includes firms that mainly attend the civil construction sector. Current research analyzed the timber production chain. Data were retrieved from eleven semi-structured interviews with timber firms, which were later transcribed and analyzed. Results show that there is actually no structured timber production chain and the links in the process exist separately and without any integration. This fact is due to the lack of inputs and the recent emergence of the municipality's forest sector.

\footnotetext{
Mestranda em Agronegócios pelo Programa de Pós-Graduação em Agronegócios da Universidade Federal do Rio Grande do Sul (UFRGS), Brasil; E-mail: carolinesoaresef14@hotmail.com.

** Engenheira Agrícola; Doutora em Agronegócios; Docente Associada da Universidade Federal do Pampa (UNIPAMPA) Campus São Gabriel (RS), Brasil.

*** Administrador; Doutor em Ciência Florestal; Docente Adjunto da Universidade Federal do Pampa (UNIPAMPA), Campus São Gabriel (RS), Brasil.
} 
KEY WORDS: Production chain; Timber; Forest sector.

\section{INTRODUÇÃO}

No Brasil, desde 1960, existe uma área significativa de florestas plantadas com espécies de Pinus e Eucalyptus. Na busca por ampliar a oferta de madeira e incentivar as empresas que utilizam como matéria-prima na reposição florestal, de 1967 até 1986, foram reflorestados no Brasil cerca de 6 milhões de hectares (BUAINAIN; BATALHA, 2007).

Segundo a Associação Brasileira de Produtores de Florestas Plantadas ABRAF (2012), o Brasil possui 6.515.844 hectares de florestas plantadas de Pinus e Eucalyptus, ocupando o $7^{\circ}$ lugar no ranking mundial de florestas plantadas e possui 4,73 milhões de empregos gerados.

O Estado do Rio Grande do Sul possui uma área de 445.004 hectares de florestas plantadas para produção de matéria-prima e, segundo a Fundação de Economia e Estatística - FEE (2012), produz $1.266 .497 \mathrm{~m}^{3}$ de madeira para a lenha, $39.870 \mathrm{~m}^{3}$ de madeira em toras e 20.216 toneladas destinadas a resinagem.

Desde 2003, o Rio Grande do Sul vem reestruturando a sua paisagem com programas florestais, com a finalidade de expandir silvicultura da região (SANTOS et al., 2007). A região da Fronteira Oeste do Estado recebeu relevantes investimentos de empresas, tanto no segmento de produção quanto de beneficiamento e processamento da madeira.

Vasconcellos e Benedetti (2011) avaliaram a evolução da cobertura florestal nos municípios da microrregião Campanha Central entre os anos de 2000 e 2010 e constataram que os municípios que apresentaram cobertura florestal mais significativa dessa região foram Rosário do Sul e São Gabriel, com 39\% e 33\%, respectivamente, da área total da microrregião.

O município de São Gabriel localiza-se na região da metade Sul do Estado do Rio Grande do Sul, entre as coordenadas geográficas de 3046’42" e 29 53 '28” de Latitude Sul e 54 52'50" e 5352'01" de Longitude Oeste, inserido no bioma Pampa (IBGE, 2012). O levantamento de informações pode servir de subsídio para ações 
de políticas públicas do setor florestal regional. A importância deste trabalho está na reflexão sobre as dificuldades estruturais e organizacionais do setor florestal no município de São Gabriel e na região da Fronteira Oeste.

Em função da recente reestruturação do setor florestal no Sul do Estado do Rio Grande do Sul, este trabalho caracterizou e analisou a cadeia produtiva da madeira serrada no município de São Gabriel.

\section{MATERIAL E MÉTODOS}

Primeiramente, fez-se um levantamento bibliográfico com materiais sobre cadeias produtivas e cadeia produtiva da madeira serrada. Foram elaborados três roteiros de entrevistas, com questões semiestruturadas, direcionados para:

(a) Insumos;

(b) Indústrias madeireiras e serrarias;

(c) Indústrias beneficiadoras de madeira: fabricas de móveis e esquadrias.

Para analisar o mercado madeireiro do município de São Gabriel (RS) foi necessário conhecer os três segmentos da cadeia produtiva que são produção de matéria-prima, industrialização e comercialização. Na etapa inicial exploratória, o objetivo foi delimitar as empresas do setor madeireiro que seriam investigadas. Para esta definição, verificaram-se as empresas que estavam registradas e legalizadas na Prefeitura Municipal de São Gabriel.

Foram estudados três segmentos que comercializam ou utilizam matériaprima florestal na cidade de São Gabriel (RS). Nestes três segmentos foram analisadas quatro empresas fornecedoras de insumos, cinco serrarias e duas fábricas de móveis, conforme detalha o Quadro 1 que relaciona as empresas investigadas 
Quadro 1. Descrição das empresas pertencentes aos elos investigados

\begin{tabular}{|c|c|c|c|}
\hline $\begin{array}{l}\text { Elo da Cadeia } \\
\text { Produtiva }\end{array}$ & $\begin{array}{c}\mathbf{N}^{o} \text { de } \\
\text { empresas } \\
\text { pesquisadas }\end{array}$ & Codificação dos entrevistados & Descrição \\
\hline \multirow{4}{*}{$\begin{array}{l}\text { Insumos de } \\
\text { produção }\end{array}$} & \multirow{4}{*}{4} & $\begin{array}{l}\text { Empresa Fornecedora de Insumos } \\
\qquad 1 \text { - EFI1; }\end{array}$ & \multirow{4}{*}{$\begin{array}{l}\text { Os insumos não } \\
\text { abastecem o } \\
\text { setor florestal do } \\
\text { município }\end{array}$} \\
\hline & & $\begin{array}{l}\text { Empresa Fornecedora de Insumos } \\
\qquad 2 \text { - EFI2; }\end{array}$ & \\
\hline & & $\begin{array}{l}\text { Empresa Fornecedora de Insumos } \\
\qquad 3 \text { - EFI3; }\end{array}$ & \\
\hline & & $\begin{array}{l}\text { Empresa Fornecedora de Insumos } \\
\qquad 4 \text { - EFI } 4\end{array}$ & \\
\hline Produção & 0 & & $\begin{array}{l}\text { Não há povoamentos } \\
\text { florestais no } \\
\text { município que } \\
\text { abasteçam as serrarias } \\
\text { e fábricas de móveis } \\
\text { locais. }\end{array}$ \\
\hline \multirow{5}{*}{ Industrialização } & \multirow{5}{*}{5} & Madeireira 1 - M1 & \multirow{5}{*}{ Serrarias } \\
\hline & & Madeireira 2 - M2 & \\
\hline & & Madeireira 3 - M3 & \\
\hline & & Madeireira 4 - M4 & \\
\hline & & Madeireira 5 - M5 & \\
\hline \multirow{2}{*}{ Comercialização } & \multirow{2}{*}{2} & Fábrica de Móveis 1 - FM1 & \multirow{2}{*}{ Fábricas de móveis } \\
\hline & & Fábrica de Móveis 2 - FM2 & \\
\hline
\end{tabular}

Fonte: Dados dos autores, 2013.

O tipo de método de pesquisa utilizado foi a entrevista pessoal. Neste tipo de método, conforme Malhotra (2001), o entrevistado vê o questionário e se posiciona face a face com o entrevistador. Dessa forma, é possível fazer perguntas consistentes e complexas.

Um roteiro de questões consiste em uma técnica estruturada para coleta de dados, composto por uma série de perguntas, escritas ou verbais, que um 
entrevistado deve responder. Este conjunto formal de perguntas tem como objetivo obter informações dos entrevistados (MALHOTRA, 2001).

O roteiro de questões partiu da definição de cadeia produtiva, proposta por Gereffi (1999), onde uma cadeia produtiva é composta por empresas que interagem em um sistema produtivo visando à oferta de produtos para o mercado consumidor. É composta ainda por fornecedores de insumos (empresas que ofertam matéria-prima para o sistema produtivo), sistema de produção (propriedade rural que produz madeira), agroindústria ou indústria de processamento (tem a função de beneficiar ou transformar produtos in natura), comercialização ou distribuição, consumidor final, ambiente institucional e ambiente organizacional. A coleta de dados primários ocorreu nos meses de junho de 2012 a julho de 2013. As entrevistas com as empresas foram realizadas pessoalmente. Na sequência, após a obtenção das informações, procedeu-se à transcrição das respostas, à análise descritiva dos dados coletados e à interpretação dos resultados, que serão descritos a seguir.

\section{RESULTADOS E DISCUSSÕES}

A presente pesquisa propõe, portanto, uma caracterização da cadeia produtiva da madeira no município de São Gabriel (RS), a fim de verificar a existência de integração entre os elos dessa cadeia produtiva.

\subsection{CARACTERIZAÇÃO DA CADEIA PRODUTIVA}

Uma cadeia produtiva é composta por empresas que interagem em um sistema produtivo visando à oferta de produtos e serviços para o mercado consumidor, podendo este ser local, regional ou global. É, desse modo, composta por fornecedores de insumos (empresas que ofertam matéria-prima para o sistema produtivo), sistema de produção (propriedade rural que trabalha com produção de grãos, madeira, etc.), agroindústria ou indústria de processamento (tem a função de beneficiar ou transformar produtos in natura), comercialização ou distribuição (realizada por atacadistas, varejistas, produtores, etc.), consumidor final, ambiente institucional e ambiente organizacional (GEREFFI, 1999). 
Segundo Couto, Hyun e Ioshida (2006), a produção de insumos consiste na produção de mudas, sementes, adubos, fertilizantes, defensivos, embalagens, dentre outros itens, que são supridores do elo produção (segundo elo), que é composto por proprietários rurais e empresas agropecuárias, que se dedicam à produção de produtos primários.

O sistema produtivo, ou produção, é a atividade de transformação (processo) de matéria-prima em bens de consumo (produtos). Esta transformação da matériaprima florestal resulta em madeira serrada, cavaco, painéis de fibra, compensado, dentre outros (SNIF, 2012).

Industrialização é o elo intermediário que representa as organizações responsáveis pela transformação das matérias-primas em produtos finais destinados ao consumidor (LENGLER; RATHMANN, 2006).

Conforme Pierro (2012), o produto industrializado é aquele que passa por um processo de transformação, modificação, composição, agregação ou agrupamento de componentes, de modo que resulte o produto diverso do que inicialmente foi empregado no processo.

A comercialização consiste no processo de transferência das matérias-primas e alimentos do produtor ao consumidor para que os bens e serviços produzidos satisfaçam as preferências dos consumidores. Também representa um processo social através do qual a estrutura de demanda de bens e serviços econômicos é antecipada ou ampliada e satisfeita através da concepção, promoção, intercâmbio e distribuição física de tais bens e serviços (BARROS, 2007). Um estudo de cadeia de produção possibilita a apreensão de dados relacionados aos membros da cadeia produtiva e também aos demais atores que intervêm na cadeia, além de características de sua organização. A abordagem de tais relações permite a exploração de discussões sobre aspectos econômicos, políticos e sociais (YUBA, 2001).

Verificou-se na pesquisa que o setor de produção da madeira não está presente no município e, consequentemente, a matéria-prima utilizada no processo não é adquirida nas empresas analisadas no município. A seguir, serão descritos os elos presentes no município, que são: empresas fornecedoras de insumos, madeireiras e fábricas de móveis e esquadrias. 


\subsubsection{As Empresas Fornecedoras de Insumos}

O Quadro 2 apresenta as características das empresas fornecedoras de insumos. Todas as empresas fornecedoras de insumos locais atuam no município há mais de 10 anos. O motivo pelo qual se instalaram em $50 \%$ dos casos foi devido ao fato de ser empresa familiar, $25 \%$ por incentivos fiscais e o restante das empresas não apresentou motivo aparente. Nenhum dos estabelecimentos investigados possui filial em outra cidade. A maioria (75\%) presta assistência técnica aos seus compradores.

Quadro 2. Caracterização das Empresas Fornecedoras de Insumos

\begin{tabular}{|l|c|c|c|c|}
\hline \multicolumn{1}{|c|}{ Questão } & EFI1 & EFI2 & EFI3 & EFI4 \\
\hline $\begin{array}{l}\text { Tempo de atuação } \\
\text { da empresa em São } \\
\text { Gabriel }\end{array}$ & 30 anos & 25 anos & 34 anos & 10 anos \\
\hline $\begin{array}{l}\text { Motivo da escolha pelo } \\
\text { município }\end{array}$ & $\begin{array}{c}\text { Empresa } \\
\text { familiar }\end{array}$ & Empresa familiar & Outra definição & Incentivos fiscais \\
\hline Filial em outra cidade & Não & Não & Não & Não \\
\hline Tipo de mão de obra & $\begin{array}{l}\text { Engenheiro } \\
\text { Agrônomo }\end{array}$ & $\begin{array}{c}\text { Egrônomo e mão de } \\
\text { obra familiar }\end{array}$ & Especializada & Gestor ambiental \\
\hline Assistência técnica & Não & Sim & Não & Não \\
\hline
\end{tabular}

Fonte: Dados dos autores, 2013.

O Quadro 3 apresenta os resultados do fornecimento da matéria-prima. A matéria-prima utilizada na produção de insumos do setor florestal não é adquirida no mercado local. Apenas uma das empresas entrevistadas presta serviços de assistência técnica aos seus clientes. Conhecendo os produtos comercializados pelas empresas, pode-se observar que todas trabalham com mudas, a EFI2 (empresa fornecedora de insumo 2) também vende arranjos florais e a $\mathrm{EFI} 3$ trabalha com insumos agropecuários. As mudas florestais mais vendidas nas EFI1 e EFI4 são espécies exóticas, nativas, frutíferas, coníferas e ornamentais, na EFI2 são basicamente frutíferas e ornamentais e na $\mathrm{EFI} 3$ são frutíferas, nativas e ornamentais. 
Quadro 3. Fornecimento de Matéria-Prima

\begin{tabular}{|c|c|c|c|c|}
\hline Questão & EFI1 & EFI2 & EFI3 & EFI4 \\
\hline $\begin{array}{c}\text { Origem dos } \\
\text { Fornecedores }\end{array}$ & $\begin{array}{c}\text { Monte Negro e } \\
\text { Ceasa }\end{array}$ & $\begin{array}{c}\text { Pareci (RS) e } \\
\text { Papa léguas }\end{array}$ & Vale do Caí & Paraná \\
\hline $\begin{array}{c}\text { Prestação de Serviços } \\
\text { aos clientes }\end{array}$ & Sim & Sim & Sim & Sim \\
\hline $\begin{array}{c}\text { Produtos } \\
\text { comercializados }\end{array}$ & Mudas & $\begin{array}{c}\text { Mudas e } \\
\text { arranjos }\end{array}$ & $\begin{array}{c}\text { Mudas e } \\
\text { insumos }\end{array}$ & Mudas \\
\hline $\begin{array}{c}\text { Espécies florestais mais } \\
\text { vendidas }\end{array}$ & $\begin{array}{c}\text { Exóticas, } \\
\text { coníferas, } \\
\text { nativas, } \\
\text { frutíferas e } \\
\text { ornamentais }\end{array}$ & $\begin{array}{c}\text { Frutíferas e } \\
\text { ornamentais }\end{array}$ & $\begin{array}{c}\text { Nativas, } \\
\text { frutíferas e } \\
\text { ornamentais }\end{array}$ & $\begin{array}{c}\text { Exótivas, frutíferas, } \\
\text { conáferas, } \\
\text { e ornamentais }\end{array}$ \\
\hline $\begin{array}{c}\text { Há aumento na } \\
\text { demanda por mudas }\end{array}$ & Sim & Não & Não & Sim \\
\hline
\end{tabular}

Fonte: Dados dos autores, 2013.

Conforme o Quadro 3, as quatro empresas de insumos que estão localizadas em São Gabriel compram os seus produtos de fornecedores localizados em outros municípios e revendem para as empresas da cidade de São Gabriel (RS).

O Quadro 4 apresenta os aspectos da comercialização de insumos florestais.

No elo de comercialização, as principais exigências dos compradores segundo os respondentes são: a preocupação com a obtenção de mudas saudáveis e de qualidade, atendimento e melhor preço dos produtos. A falta de conhecimento dos métodos silviculturais para a condução das mudas foi observado por $75 \%$ das empresas entrevistadas, todas elas prestam serviços de entrega aos seus clientes.

As dificuldades na comercialização dos produtos mencionadas pelos respondentes foram: disponibilidade de mão de obra (50\% entrevistados); tributação (25\%); e 50\% dos entrevistados não identificaram nenhum problema na comercialização. 
Quadro 4. Comercialização

\begin{tabular}{|l|c|c|c|c|}
\hline \multicolumn{1}{|c|}{ Tema abordado } & EFI1 & EFI2 & EFI3 & EFI4 \\
\hline $\begin{array}{l}\text { Exigência dos } \\
\text { compradores }\end{array}$ & $\begin{array}{c}\text { Muda } \\
\text { certificada e } \\
\text { saudável }\end{array}$ & $\begin{array}{c}\text { Atendimento } \\
\text { e preço }\end{array}$ & $\begin{array}{c}\text { Qualidade e } \\
\text { sanidade }\end{array}$ & Desconhece \\
\hline $\begin{array}{l}\text { Há falta de conhecimento } \\
\text { silvicultural dos } \\
\text { compradores }\end{array}$ & Sim & Sim & Sim & Não \\
\hline $\begin{array}{l}\text { Serviço de entrega dos } \\
\text { produtos }\end{array}$ & Sim & Sim & Sim & Sim \\
\hline $\begin{array}{l}\text { Dificuldades na } \\
\text { comercialização }\end{array}$ & Não & $\begin{array}{c}\text { Mão de obra } \\
\text { qualificada }\end{array}$ & $\begin{array}{c}\text { Mão de obra } \\
\text { qualificada e } \\
\text { tributação }\end{array}$ & Não \\
\hline
\end{tabular}

Fonte: Dados dos autores, 2013.

\subsubsection{As madeireiras}

O Quadro 5 apresenta as características de cada empresa madeireira instalada no município de São Gabriel (RS).

Na primeira questão foi indagado aos proprietários das madeireiras há quanto tempo a sua empresa está atuando na cidade e porque optaram por se instalar no município de São Gabriel. Todos os comerciantes atuam na cidade há mais de dez anos, ou seja, não há empresas novas instalando-se no município. As empresas entrevistadas se caracterizam por serem familiares.

Os respondentes afirmaram que não possuem filiais em outras cidades.

Quanto aos clientes-alvo das empresas, $40 \%$ dos entrevistados ressaltaram que seus clientes são produtores rurais, $40 \%$ são fábricas de móveis. Cerca de $80 \%$ ressaltaram que ofertam seus produtos para indústrias da construção civil. 
Quadro 5. Caracterização das Empresas Madeireiras Pesquisadas

\begin{tabular}{|l|c|c|c|c|c|}
\hline \multicolumn{1}{|c|}{ Questão } & M1 & M2 & M3 & M4 & M5 \\
\hline $\begin{array}{l}\text { Tempo de } \\
\text { atuação }\end{array}$ & 13 anos & 25 anos & 35 anos & 10 anos & 30 anos \\
\hline $\begin{array}{l}\text { Motivo da } \\
\text { escolha pelo } \\
\text { município }\end{array}$ & $\begin{array}{c}\text { Empresa } \\
\text { familiar }\end{array}$ & $\begin{array}{c}\text { Empresa } \\
\text { familiar }\end{array}$ & $\begin{array}{c}\text { Pesquisa de } \\
\text { mercado }\end{array}$ & $\begin{array}{c}\text { Empresa } \\
\text { familiar }\end{array}$ & $\begin{array}{c}\text { Empresa } \\
\text { familiar }\end{array}$ \\
\hline Filial & Não & Não & Não & Não & Não \\
\hline $\begin{array}{l}\text { Clientes-alvo da } \\
\text { empresa }\end{array}$ & $\begin{array}{c}\text { Produtor } \\
\text { rural }\end{array}$ & $\begin{array}{c}\text { Fábricas } \\
\text { de móveis, } \\
\text { produtor rural, } \\
\text { construção civil }\end{array}$ & $\begin{array}{c}\text { Fábricas de } \\
\text { móveis e } \\
\text { indústrias da } \\
\text { construção } \\
\text { civil }\end{array}$ & $\begin{array}{c}\text { Indústria da } \\
\text { construção } \\
\text { civil }\end{array}$ & $\begin{array}{c}\text { Indústrias da } \\
\text { construção } \\
\text { civil }\end{array}$ \\
\hline
\end{tabular}

Fonte: Dados dos autores, 2013.

O processo de obtenção e caracterização da matéria-prima e equipamentos para o processo de industrialização é detalhado no Quadro 6.

As madeireiras do município de São Gabriel (RS) não possuem área florestal própria, consequentemente, todas as madeireiras buscam matéria-prima em outras regiões. Cerca de $40 \%$ dos entrevistados compram madeira de outros Estados. Por volta de $90 \%$ dos entrevistados afirmaram que a oferta de madeira não é abundante no mercado local.

Quando se trata da oferta de madeira oriunda de floresta nativa, 100\% dos proprietários afirmam que não é utilizada no processo produtivo. Isto se deve, segundo os respondentes, à fiscalização rígida no município. Em relação às espécies florestais com que as empresas trabalham, todos os entrevistados disseram que trabalham com Pinus e Eucalipto. Destes, 60\% também trabalham com Cedro.

A evolução do mercado madeireiro local é observada por $60 \%$ dos respondentes, porém, apenas $20 \%$ das madeireiras adquirem as ferramentas de desdobro da madeira no mercado local, a maioria dos proprietários encontra dificuldades em obtê-las no município, em alguns casos pelo alto custo das ferramentas. 
Quadro 6. Caracterização da Obtenção da Matéria-Prima e Equipamentos

\begin{tabular}{|l|c|c|c|c|c|}
\hline \multicolumn{1}{|c|}{ Tema Abordado } & M1 & M2 & M3 & M4 & M5 \\
\hline $\begin{array}{l}\text { Possui área florestal } \\
\text { própria }\end{array}$ & Não & Não & Não & Não & Não \\
\hline $\begin{array}{l}\text { Origem da Madeira } \\
\text { São Sepé } \\
\text { (RS) e } \\
\text { Caçapava } \\
\text { do Sul } \\
\text { (RS) }\end{array}$ & $\begin{array}{c}\text { MT, RO } \\
\text { e RS }\end{array}$ & $\begin{array}{c}\text { Bento } \\
\text { Gonçalves } \\
\text { (RS), } \\
\text { Gramado } \\
\text { (RS) e } \\
\text { Cruz Alta } \\
\text { (RS) }\end{array}$ & $\begin{array}{c}\text { MT, } \\
\text { Sobradinho } \\
\text { (RS) e } \\
\text { Piratini } \\
\text { (RS) }\end{array}$ & $\begin{array}{c}\text { Piratini } \\
\text { (RS) e } \\
\text { Santa Cruz } \\
\text { do Sul (RS) }\end{array}$ \\
\hline $\begin{array}{l}\text { Oferta de madeira é } \\
\text { abundante no mercado } \\
\text { local }\end{array}$ & Não & Não & Não & Não & Sim \\
\hline $\begin{array}{l}\text { Oferta de madeira } \\
\text { oriunda de floresta nativa }\end{array}$ & Não & Não & Não & Não & Não \\
\hline $\begin{array}{l}\text { Espécies de árvores } \\
\text { utilizadas no processo de } \\
\text { produção }\end{array}$ & $\begin{array}{c}\text { Eucalipto } \\
\text { e Pinus }\end{array}$ & $\begin{array}{c}\text { Eucalipto, } \\
\text { Cedro e }\end{array}$ & $\begin{array}{c}\text { Eucalipto, } \\
\text { Pinus e } \\
\text { Cedro }\end{array}$ & $\begin{array}{c}\text { Eucalipto, } \\
\text { Cedro e }\end{array}$ & Eucalipto e \\
Pinus
\end{tabular}

Fonte: Dados dos autores, 2013.

Apenas 20\% das empresas entrevistadas possuem mais de dez funcionários no processo de produção. O grau de escolaridade pode ser considerado baixo no grupo de funcionários, pois apenas $40 \%$ concluíram o ensino médio e $20 \%$ possuem o ensino superior incompleto, sendo que todos estes colaboradores possuem idade superior a 18 anos.

Quanto aos critérios de contratação dos funcionários, variam de empresa para empresa. Os critérios elencados pelos respondentes foram: $40 \%$ dos 
colaboradores são contratados por boas referências, $20 \%$ pelo interesse e confiança no funcionário, $20 \%$ disseram que são exigidas experiência e prática no tipo de serviço a ser realizado e $20 \%$ afirmaram que não apresentam nenhum tipo de critério de contratação.

Quanto à existência de treinamento para os colaboradores contratados, as atividades de qualificação profissional são realizadas por apenas $20 \%$ das empresas. Por isso, cerca de $80 \%$ das empresas investigadas apresentam dificuldades com qualificação de mão de obra.

Todas as empresas disponibilizam os EPIs (equipamentos de proteção individual) e, destas, $80 \%$ obtêm boa aceitação por parte do colaborador no uso de equipamentos. Todas as empresas realizam ações para a prevenção de acidentes, na forma de palestras, contratando um técnico em segurança do trabalho ou em alguns casos fornecendo cursos.

O Quadro 7 caracteriza as empresas do município que trabalham com beneficiamento da madeira. No município de São Gabriel, 80\% das madeireiras instaladas realizam o processo de beneficiamento da madeira. Apenas M5 não apresenta estas características (Quadro 7), pois recebem o produto em tábuas e não realizam o beneficiamento.

Quanto às máquinas e equipamentos que as empresas entrevistadas relataram possuir, $60 \%$ possuem serras fitas e circulares para auxiliar no processo, $40 \%$ trabalham com plainas e $20 \%$ apenas com a desempenadeira.

Os equipamentos usados no processo são, em sua maioria, tratores, motosserras e caminhões (40\% das empresas). Além disso, $20 \%$ possuem camionete e carregadores. Todas as madeireiras trabalham com a comercialização de tábuas. Destas, $40 \%$ trabalham com o desdobro da madeira, $40 \%$ fabricam casas volantes e saleiros cobertos e apenas $20 \%$ das madeireiras produzem casas pré-fabricadas. Os resíduos gerados pelo processo de produção, quando reaproveitados, no caso de $60 \%$ das empresas respondentes, são levados pelos próprios clientes para serem reutilizados como, por exemplo, na queima de calcário. Todas as empresas são legalizadas no município, porém, a metade delas tem conhecimento do selo de certificação ambiental, mas nenhuma possui o selo nos seus produtos. A empresa M5 não trabalha com beneficiamento da madeira, apenas comercializa o produto final, portanto não foi analisado este aspecto no Quadro 8. 
Quadro 7. Caracterização do Beneficiamento da Madeira

\begin{tabular}{|l|c|c|c|c|}
\hline \multicolumn{1}{|c|}{ Questão } & M1 & M2 & M3 & M4 \\
\hline $\begin{array}{l}\text { Equipamentos } \\
\text { utilizados no desdobro } \\
\text { da madeira }\end{array}$ & $\begin{array}{c}\text { Serras circulares, } \\
\text { serras fitas e } \\
\text { plainas }\end{array}$ & $\begin{array}{c}\text { Serras circulares, } \\
\text { serras fitas e } \\
\text { desempenadeira }\end{array}$ & $\begin{array}{c}\text { Serras } \\
\text { circulares e } \\
\text { serras fitas }\end{array}$ & $\begin{array}{c}\text { Serras } \\
\text { circulares e } \\
\text { plainas }\end{array}$ \\
\hline $\begin{array}{l}\text { Equipamentos } \\
\text { indiretamente usados } \\
\text { no processo de } \\
\text { produção }\end{array}$ & $\begin{array}{c}\text { Trator, caminhão } \\
\text { e carregadores }\end{array}$ & Nenhum & $\begin{array}{c}\text { Trator e } \\
\text { motosserra }\end{array}$ & $\begin{array}{c}\text { Motosserra, } \\
\text { caminhão e } \\
\text { camionete }\end{array}$ \\
\hline $\begin{array}{l}\text { Produtos fabricados } \\
\text { pela empresa }\end{array}$ & $\begin{array}{c}\text { Desdobro de } \\
\text { toras, saleiros, } \\
\text { tábuas, casas } \\
\text { volantes e casas } \\
\text { pré- fabricadas }\end{array}$ & $\begin{array}{c}\text { Tábuas de } \\
\text { madeira }\end{array}$ & $\begin{array}{c}\text { Desdobro } \\
\text { e tábuas, } \\
\text { casas } \\
\text { volantes e } \\
\text { saleiros }\end{array}$ & $\begin{array}{c}\text { Tábuas de } \\
\text { madeira }\end{array}$ \\
\hline $\begin{array}{l}\text { Resíduos gerados são } \\
\text { reaproveitados }\end{array}$ & Sim & Não & Sim & Sim \\
\hline Empresa está legalizada & Sim & Sim & Sim & Sim \\
\hline $\begin{array}{l}\text { Conhecimento sobre } \\
\text { os benefícios da } \\
\text { certificação ambiental }\end{array}$ & Sim & Não & Não & Sim \\
\hline
\end{tabular}

Fonte: Dados dos autores, 2013.

A empresa M5 não está descrita no quadro acima porque a madeira que é recebida na serraria já está beneficiada, ou seja, o processo de industrialização não está presente nesta empresa, o material que será comercializado com o consumidor final já possui o formato e dimensões de tábuas de madeira.

Os aspectos gerais da comercialização dos produtos do setor madeireiro na cidade de São Gabriel (RS) são descritos no Quadro 8. Todas as empresas disponibilizam transporte do produto até o cliente. Cerca de $60 \%$ dos respondentes apontaram que comercializam seus produtos em cidades vizinhas, não atendendo apenas a demanda do mercado local.

Quanto ao processo de comercialização, 20\% das empresas investigadas apresentam dificuldades na comercialização, devido à falta de matéria-prima para a industrialização. Dos entrevistados, $80 \%$ indicaram que não existem empresas concorrentes que interferem na comercialização, pois cada empresa industrializa e comercializa os produtos madeireiros para seus próprios clientes. 
No setor florestal do município de São Gabriel (RS) é possível observar que as empresas atuantes são familiares e que não utilizam mão de obra especializada. Nenhuma das empresas investigadas possui plantio florestal próprio para atender à sua demanda.

Considerando a análise feita nas empresas, os proprietários não apresentaram interesse em expandir a comercialização dos seus produtos para outras regiões, reafirmando o seu interesse em suprir apenas a demanda do mercado local. A questão ambiental de implantação dos selos de certificação florestal é desconhecida pela maioria das empresas e, segundo os entrevistados, o público-alvo não se mostra exigente neste aspecto. Para os respondentes, as políticas públicas não são eficazes, pois não há incentivo para a criação de redes de cooperação como, por exemplo, Arranjos Produtivos Locais (APLs) para fortalecer o setor madeireiro no município.

No município de São Gabriel (RS) não há a participação e a interação de empresas e agentes econômicos, políticos e sociais, com foco em um conjunto específico de atividades econômicas. Por isso, é necessário um maior apoio governamental, formalizado através de políticas públicas, que incentivem a instalação de empresas de insumos e produção para que estas também estejam presentes no município, evitando a obrigatoriedade de suprimento de matéria-prima oriunda de outras regiões.

Quadro 8. Caracterização da Comercialização

\begin{tabular}{|l|c|c|c|c|c|}
\hline \multicolumn{1}{|c|}{ Tema abordado } & M1 & M2 & M3 & M4 & M5 \\
\hline $\begin{array}{l}\text { Disponibiliza transporte } \\
\text { do produto até o cliente }\end{array}$ & $\operatorname{Sim}$ & $\operatorname{Sim}$ & $\operatorname{Sim}$ & Sim & Sim \\
\hline $\begin{array}{l}\text { Dificuldades na } \\
\text { comercialização }\end{array}$ & Nenhuma & Nenhuma & $\begin{array}{c}\text { Falta de } \\
\text { matéria-prima }\end{array}$ & Nenhum & Nenhum \\
\hline $\begin{array}{l}\text { Comercializa com cidades } \\
\text { vizinhas }\end{array}$ & $\operatorname{Sim}$ & $\operatorname{Sim}$ & $\operatorname{Sim}$ & Não & Não \\
\hline $\begin{array}{l}\text { Empresas concorrentes } \\
\text { interferem na } \\
\text { comercialização }\end{array}$ & $\operatorname{Sim}$ & Não & Não & Não & Não \\
\hline
\end{tabular}

Fonte: Dados dos autores, 2013. 


\subsubsection{Fábricas de móveis e esquadrias}

O Quadro 9 apresenta as características de cada fábrica de móveis instalada no município de São Gabriel (RS).

O setor de fábrica de móveis no município de São Gabriel (RS) é abastecido por duas empresas que são responsáveis por atender a demanda dos produtos no comércio e nas residências. Uma das empresas é familiar e a outra optou por esta região devido a incentivos fiscais e também possui filial em outra cidade.

Quadro 9. Caracterização da Empresa

\begin{tabular}{|l|c|c|}
\hline \multicolumn{1}{|c|}{ Questão } & FM1 & FM2 \\
\hline Tempo de atuação da empresa & 6 anos & 7 anos \\
\hline Motivo da escolha pelo município & Incentivos fiscais & Empresa familiar \\
\hline Filial em outra cidade & Sim & Não \\
\hline Clientes-alvo da empresa & Residencial e Comercial & Residencial e Comercial \\
\hline
\end{tabular}

Fonte: Dados dos autores, 2013.

O processo de obtenção e caracterização da matéria-prima e equipamentos para o processo de industrialização será detalhado no Quadro 10.

As empresas do município não possuem área florestal própria, portanto, a matéria-prima é terceirizada. O material de madeira processada do tipo MDF e aglomerado não são encontrados no mercado local, apenas tábuas de madeira que a empresa FM2 comercializa com madeireira localizada no município de São Gabriel. As matérias-primas usadas na fabricação dos móveis na empresa FM1 são ferragens, pois o material utilizado é apenas o MDF, na empresa FM2 são usados verniz e tinta seladora, pois também trabalham com reforma de móveis. 
Quadro 10. Caracterização da Obtenção da Matéria-Prima e Equipamentos

\begin{tabular}{|l|c|c|}
\hline \multicolumn{1}{|c|}{ Tema Abordado } & FM1 & FM2 \\
\hline Obtenção da matéria-prima florestal & Terceirizada & Terceirizada \\
\hline Origem da madeira e painéis de madeira & RS, Carazinho & $\begin{array}{c}\text { RS, Passo Fundo, Santa Cruz e } \\
\text { Madeireira SG }\end{array}$ \\
\hline Espécies utilizadas na produção & MDF & $\begin{array}{c}\text { MDF, Aglomerado, Pinus e } \\
\text { Eucalipto }\end{array}$ \\
\hline $\begin{array}{l}\text { Exigência de notas fiscais que comprovem } \\
\text { procedência de madeira nativa }\end{array}$ & Sim & Sim \\
\hline Possui área florestal própria & Não & Não \\
\hline Tipos de madeira processada & MDF & MDF e Aglomerado \\
\hline Outras matérias-primas utilizadas & Ferragens & Tinta Seladora e Verniz \\
\hline
\end{tabular}

Fonte: Dados dos autores, 2013.

O quadro de funcionários só pôde ser analisado em uma das empresas contatadas, pois a fábrica de móveis FM2 não possui um quadro de funcionários, apenas o proprietário atende a demanda dos serviços. Considerando a fábrica de móveis FM1, os funcionários possuem ensino fundamental completo e não há critérios para a contratação de novos colaboradores. As dificuldades com a contratação são devido à falta de qualificação dos candidatos no mercado. A empresa disponibiliza os EPIs com o intuito de prevenção de acidentes.

As atividades desenvolvidas nas empresas são basicamente a fabricação de móveis, porém, em uma das empresas também é feita a restauração de móveis. As empresas estão devidamente legalizadas no município e apenas uma delas tem conhecimento sobre os benefícios do selo de certificação ambiental. Os equipamentos utilizados no processo de fabricação da FM1 são serras fitas, plainas, desempenadeiras, serras circulares, furadeira, lixadeira, prensa, esmeril e afiador e na empresa FM2 são basicamente serras circulares, plainas e lixadeira. Os resíduos gerados neste processo não são reaproveitados por nenhuma das empresas.

Os aspectos gerais da comercialização dos produtos das fábricas de móveis no município de São Gabriel (RS) são descritos no Quadro 11.

Analisando a comercialização, os mercados atingidos pela empresa FM1 são local, estadual e regional, na empresa FM2 são local e regional apenas. As duas 
empresas disponibilizam transporte do produto até o cliente. Ambas comercializam seus produtos com cidades vizinhas e apenas uma fábrica de móveis relatou sobre ter concorrentes interferindo nesta questão.

Quadro 11. Comercialização

\begin{tabular}{|l|c|c|}
\hline \multicolumn{1}{|c|}{ Tema abordado } & FM1 & FM2 \\
\hline $\begin{array}{l}\text { Mercados Geográficos Atingidos pela } \\
\text { Empresa }\end{array}$ & $\begin{array}{c}\text { Local, Estadual e } \\
\text { Regional }\end{array}$ & Local e Regional \\
\hline Transporta o produto até o cliente & Sim & Sim \\
\hline Dificuldades na comercialização & Transporte & Nenhuma \\
\hline Comercializa com cidades vizinhas & Sim & Sim \\
\hline $\begin{array}{l}\text { Empresas concorrentes interferem na } \\
\text { comercialização }\end{array}$ & Sim & Não \\
\hline
\end{tabular}

Fonte: Dados dos autores, 2013.

\subsection{AS INTER-RELAÇÕES DA CADEIA PRODUTIVA DA MADEIRA SERRADA NO MUNICÍPIO DE SÃO GABRIEL}

A Figura 1 ilustra a inter-relação dos elos da cadeira produtiva da madeira serrada presente no município de São Gabriel (RS). 


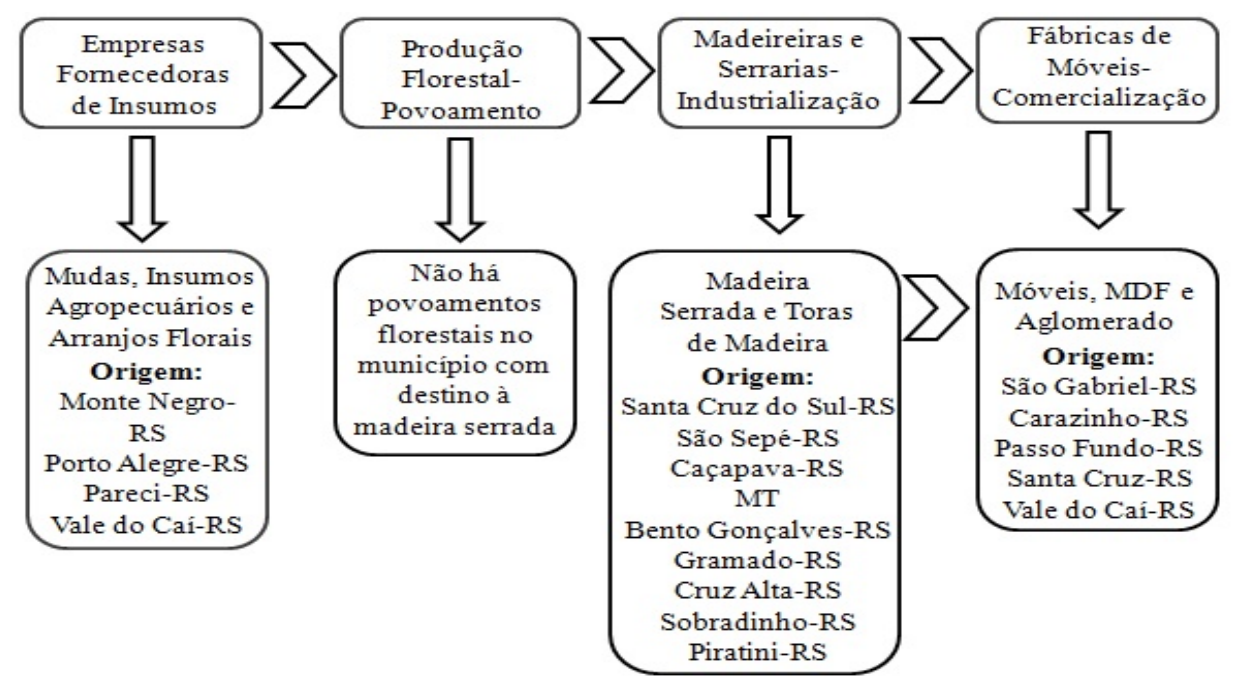

Figura 1. Fluxograma da Cadeia Produtiva da Madeira Serrada do Município de São Gabriel (RS) Fonte: Dados dos autores, 2013 e 2014.

As empresas fornecedoras de insumos do município de São Gabriel (RS) não abastecem o setor de produção florestal, devido aos povoamentos florestais com destino a madeira serrada não estarem localizados na região estudada. Consequentemente, estes elos da cadeia de produção florestal não atendem ao conceito de cadeia produtiva da madeira de Gereffi (1999) que preconiza que o fluxo de materiais deve estar interconectado objetivando o suprimento do mercado consumidor final.

Embora Santos et al. (2007) afirmem que desde 2003 o Rio Grande do Sul implantou um programa florestal com a finalidade de aumentar a produção silvícola da região, o que se constatou foi que os povoamentos florestais existentes no município de São Gabriel ainda não suprem a demanda local das madeireiras e serrarias.

Constatou-se que o elo "industrialização" supre o elo de comercialização (Figura 1). Portanto, existe apenas essa conexão entre elos localizados no município de São Gabriel (RS). Apenas uma das empresas catalogadas como empresas madeireiras e serrarias fornece o material para produção moveleira do setor de comercialização. Sendo assim, os demais elos da cadeia localizam-se em outros municípios. 
Soares et al. (2010) verificaram que umas das características das empresas do setor de celulose e papel no Brasil é a integração com o setor produtivo. Esse tipo de integração não ocorre no segmento da madeira serrada no município de São Gabriel. Portanto, não há uma atuação conjunta e articulada das empresas na região investigada.

A realização deste trabalho possibilitou um avanço do conhecimento empírico sobre as dificuldades estruturais e organizacionais do setor florestal no município de São Gabriel. Esta informação pode servir de subsídio para os gestores públicos, municipais, estaduais e federais planejarem ações estratégicas de apoio ao setor florestal, o que consequentemente se reverterá em benefícios econômicos e sociais para a região.

Por outro lado, sob o aspecto teórico, diferentemente de vários trabalhos sobre cadeias produtivas desenvolvidos, por exemplo, por Gereffi (1999) e Yuba (2001), este trabalho buscou desvendar os fatores que explicam a "desestruturação" de uma cadeia e as desvantagens estratégicas desta desarticulação.

\subsection{OS PRINCIPAIS GARGALOS DA CADEIA PRODUTIVA DA MADEIRA SERRADA NO MUNICÍPIO DE SÃO GABRIEL}

O setor florestal em São Gabriel (RS) é caracterizado por possuir empresas fornecedoras de insumos, industrialização, comercialização e beneficiadoras de madeira, porém, as empresas fornecedoras de insumos, instaladas no município, não ofertam a matéria-prima para este processo, porque os plantios florestais destinados à produção de toras de madeira para a serraria não estão presentes na região e sim em outros municípios e Estados. As empresas não operam em uma rede de cooperação e sim individualmente. Esta constatação pressiona o setor florestal local para a implantação de povoamentos de florestas plantadas, com o intuito de satisfazer a demanda local por madeira. Os resultados encontrados são corroborados por Gardiner e Moore (2014) que afirmam que há necessidade de se produzir mais madeira por unidade de área e que os produtos florestais devem ser criteriosamente gerenciados para atender às expectativas da demanda, isto é, dos consumidores finais. 
A cadeia de suprimento florestal, quando articulada, é composta por muitos negócios interconectados que são compostos por vários processos. Por exemplo, os produtores que gerenciam um "mix" de espécies florestais, os vários empreendedores que convertem árvores em toras, as serrarias que realizam o processamento mecânico da madeira, transformando-a em diversos produtos. Esta variedade de processos faz com que as atividades de integração entre aquisições, produção, distribuição e vendas, sejam muito complexas, dado que estas estão limitadas pelos trade-offs entre produção, custos de logística e distribuição e níveis de serviços (D’AMOURS; RÖNNQVIST; WEINTRAUB, 2008). Essa complexidade da gestão integrada talvez seja um dos fatores que justifique a inexistência da configuração de cadeia produtiva da madeira no caso estudado.

Para o desempenho eficaz do setor, segundo Gardiner e Moore (2014), é preciso que a cadeia produtiva da madeira esteja articulada e adote novas técnicas e tecnologias capazes de modernizar a produção, beneficiamento e comercialização, obtendo produtos florestais que sigam a sequência da cadeia produtiva inteira, desde as florestas até o uso final. Esse encadeamento de processos terá reflexos na eficácia da cadeia produtiva da madeira.

Enfim, os principais gargalos que podem estar impedindo a consolidação de uma cadeia produtiva da madeira serrada no município de São Gabriel são a falta de coordenação e de integração da cadeia produtiva e a distância geográfica entre os elos da cadeia.

\section{CONCLUSÕES}

De acordo com a análise realizada no município, observou-se que as indústrias madeireiras e as indústrias beneficiadoras de madeira recebem a matériaprima para a sua produção advinda de outras cidades e de outros Estados. Desta forma, os insumos e a produção da madeira, desde os elos iniciais, fornecimento de matérias-primas e produção (o povoamento florestal) não abastecem o município de São Gabriel.

A cadeia produtiva da madeira serrada no município de São Gabriel não funciona como um processo sequencial e articulado da produção de insumos até a 
comercialização. Os elos envolvidos neste processo trabalham separadamente, não havendo interligação entre os mesmos. Este fato ocorre devido à falta de insumos para a produção no mercado local, e a industrialização independente das empresas com o foco apenas no seu cliente final.

Sobre a importância que as redes de cooperação podem assumir para as empresas participantes, estas redes proporcionam o atendimento de diversas necessidades que dificilmente seriam atendidas caso cada uma delas tentasse obtêlas individualmente, como ocorre no setor madeireiro do município de São Gabriel (RS). Várias melhorias poderiam ocorrer nas empresas e novas perspectivas de mercado poderiam ser alcançadas com esta configuração.

\section{REFERÊNCIAS}

ABRAF. Anuário estatístico da ABRAF 2012: ano base 2011. Brasília: Associação Brasileira de Produtores de Florestas Plantadas, 2012.

BARROS, G. S. C. Economia da comercialização agrícola. Piracicaba: CEPEA/LESESALQ/USP, 2007.

BUAINAIN, A. M.; BATALHA, M. O. (Coord.). Cadeia produtiva da madeira. Brasília: Ministério da Agricultura, Pecuária e Abastecimento: IICA, 2007.

COUTO, E. X.; HYUN, M. J.; IOSHIDA, P. L. K. Caracterização, descrição e análise da cadeia produtiva de frutas orgânicas no estado de São Paulo. Ano 3. São Paulo: Jovens Pesquisadores, 2006.

D'AMOURS, S.; RÖNNQVIST, M.; WEINTRAUB, A. Using operational research for supply chain planning in the forest products industry. INFOR, n. 46, 2008.

FUNDAÇÃO DE ECONOMIA E ESTATÍSTICA - FEE. Disponível em: < http://www.fee. rs.gov.br/sitefee/pt/content/capa/index.php> . Acesso em: 06 jun. 2012.

GARDINER, B.; MOORE, J. Creating the wood supply of the future. In: FENNING, T. (Ed.). Challenges and opportunities for the world's forests in the 21st century. Edinburgh: Springer, 2014. (Forestry Sciences 81). 
GEREFFI, G. International trade and industrial upgrading in the apparel commodity chain. Journal of International Economics, v. 48, 1999.

INSTITUTO BRASILEIRO DE GEOGRAFIA E ESTATÍSTICA - IBGE. Disponível em: <http://www.ibge.gov.br/home/> . Acesso em: 08 jun. 2012.

LENGLER, L.; RATHMANN, R. Assimetria de relacionamentos na cadeia apícola do Rio Grande do Sul. Revista da FAE, Curitiba, v. 9, 2006.

MALHOTRA, N. Pesquisa de marketing: uma orientação aplicada. Porto Alegre: Bookman, 2001.

PIERRO, J. M. Material intermediário consumido no processo de industrialização. Disponível em: <http://www.jusbrasil.com.br/jurisprudencia/2182674/apelacaocivel-771227-ac-3574-sp-20020399003574-3-trf3 > . Acesso em: 02 jul. 2012.

SANTOS, O. I. B.; MAGALHÃES, A.; CHAVES, R.; BLOS, A. L. F.; SILVA, T. N. Perspectivas de desenvolvimento sustentável da metade sul do Rio Grande do Sul com base nos arranjos silvícolas emergentes e na produção de etanol a partir de celulose. In: ENCONTRO NACIONAL SOBRE GESTÃO EMPRESARIAL E MEIO AMBIENTE, 2007, Curitiba. Anais... Curitiba: ENGEMA, 2007.

SISTEMA NACIONAL DE INFORMAÇÕES FLORESTAIS - SNIF. Disponível em: < http://www.florestal.gov.br/snif/> . Acesso em: 20 abr. 2012.

SOARES, N. S.; OLIVEIRA, R. J.; CARVALHO, K. H. A.; SILVA, M. L.; JACOVINE, L. A. G.; VALVERDE, S. R. A Cadeia produtiva da celulose e do papel no Brasil. Floresta, v. 40, n. $1,2010$.

VASCONCELlOS, B. N.; BENEDETTI, A. C. P. Dinâmica temporal da cobertura florestal na microrregião campanha central do Rio Grande do Sul. Revista Eletrônica em Gestão, Educação e Tecnologia Ambiental, v. 4, n. 4, 2011.

YUBA, A. N. Cadeia produtiva de madeira serrada de eucalipto para produção sustentável de habitações. 2001. Dissertação (Mestrado em Engenharia Civil) Universidade Federal do Rio Grande do Sul, Porto Alegre, RS. 
Recebido em: 16 de setembro de 2014 Aceito em: 18 de setembro de 2015 